\title{
O registro sanitário de medicamentos e as políticas de saúde
}

\author{
Sanitary registration of medicines and health policies
}

\section{Luís Bernardo Delgado Bieber}

Advogado, Especialista em Direito Sanitário. Assistente da Direção da Agência Nacional de Vigilância Sanitária. Brasília, DF, Brasil.

Resumo: A legislação sanitária vigente no Brasil, embora se preste a cumprir os propósitos de garantir a qualidade, a eficácia e a segurança dos medicamentos colocados no mercado, não basta para defender o interesse público relativo à implementação da política de assistência farmacêutica. Não há norma que garanta a continuidade da produção e da distribuição do medicamento de interesse das políticas públicas de saúde após o fim da validade do seu registro. A partir do registro de medicamentos, a agência reguladora (vigilância sanitária) teria uma contribuição especial às políticas de saúde e, em especial à política de medicamentos, se procedesse a um verdadeiro enfrentamento dos interesses econômicos empresariais que, com não rara frequência, sobrepõem-se aos interesses da população. O artigo revisa a legislação e a doutrina sobre a matéria, concluído pela necessidade de articulação das ações de assistência farmacêutica com as de vigilância sanitária como mais um instrumento na luta pela garantia do acesso ao medicamento, e que a legislação referente ao registro de medicamentos confere às empresas reguladas um protagonismo incoerente com a nova ordem sanitária constitucional quanto às decisões relativas aos medicamentos que serão disponibilizados no mercado ou dele retirados. $O$ autor defende que, no entanto, existem disposições constitucionais e legais que fundamentam suficientemente uma atuação mais incisiva do Estado na defesa do interesse público e da continuidade de suas políticas de saúde.

Palavras chaves: Medicamento, registro sanitário; assistência farmacêutica; vigilância sanitária, medicamentos; Direito Sanitário.

Resumen: La legislación sanitaria brasileña, a pesar de adecuada a los fines de garantizar la calidad, la eficacia y la seguridad de los medicamentos introducidos en el mercado, no es suficiente para defender el interés público en la implementación de la política de atención farmacéutica. No existe una norma que garantice la continuidad de la producción y distribución de los medicamentos de interés de las políticas públicas de salud cuando de la expiración de la validad de su registro. A partir del registro, la agencia reguladora (vigilancia sanitaria) tendría una contribución especial a las políticas de salud y, en particular, a la política de medicamento, si procediera a una verdadera confrontación de los intereses económicos empresariales que, con no rara frecuencia, se superponen a los intereses de la población. El artículo revisa la legislación y la doctrina sobre el tema, concluyendo por la necesidad de articulación de las acciones de suministro de medicamentos con las de vigilancia sanitaria como un instrumento más en la lucha por garantizar el acceso al medicamento, y que la ley que trata del registro de medicamentos dá a las empresas reguladas protagonismo 
incoherente con el nuevo orden constitucional en cuanto a las decisiones sobre medicamentos para ser puestos a disposición o retirados del mercado. El autor sostiene que, sin embargo, existen disposiciones constitucionales y legales que fundamentan suficientemente un papel más incisivo del Estado en la defensa del interés público y en la continuidad de sus políticas de salud.

Palabras clave: medicamento, registro sanitario; suministro de medicamentos; vigilancia sanitaria, medicamentos; Derecho Sanitario.

\begin{abstract}
The health legislation in force in Brazil, although lends itself to fulfill the purposes of ensuring quality, effectiveness and safety of medicines that enter the market, is not enough to defend the public interest concerning the implementation of pharmaceutical care policy. There is no rule that guarantees the continuity of production and distribution of a drug of public health interest after the end of the validity of it registration. The regulatory agency (drug administration) would have a special contribution to health policies and, in particular, to medicine policy, if it came to a real confrontation of corporate economic interests that, often, overlaps the interests of the population. The article reviews the law and doctrine on the matter, concluding by the need to articulate the actions of pharmaceutical care with health surveillance, as another instrument in the effort for ensuring access to medicines, and that legislation relating to drug registration confers a protagonism to the regulated companies that is inconsistent with the new constitutional order regarding decisions on medicines to be made available or withdrawn from the market. The author argues that, however, there are constitutional and legal provisions that would allow a most incisive performance of the State in the public interest and for the continuity of their health policies.
\end{abstract}

Keywords: Medicine, sanitary registration; pharmaceutical care; sanitary surveillance, medicines; Health Law.

\title{
1 Introdução
}

O campo de atuação do Estado na área da saúde é vastíssimo. Para atender a toda a complexidade da matéria, vários são os órgãos do Sistema Único de Saúde (SUS) que se dedicam a contribuir para a construção de uma política de saúde integral e unificada. A maior estruturação de cada um desses órgãos, ao lado da especialização do seu corpo técnico, conduz ao aperfeiçoamento da atuação do órgão, na esperança de que a melhor atuação da unidade impacte positivamente para o conjunto. No entanto, essa situação sempre traz o risco de insulamento e "ensimesmamento" burocrático do órgão e seus servidores que, no cumprimento de suas atribuições deixam de reparar nas consequências de suas ações para as demais unidades do mesmo sistema.

Esse é o caso da Vigilância Sanitária que, perseguindo sua missão de atuar para eliminar, prevenir e reduzir os riscos à saúde da população, terminou por se 
alijar das demais políticas públicas de saúde, dentre as quais se destaca a de assistência farmacêutica. Apesar do grande consumo de medicamentos no Brasil, é preciso refletir acerca dos medicamentos que se têm consumido no país. Além do aprofundamento relativo às doenças enfrentadas e ao perfil epidemiológico da população brasileira, também é preciso observar a real disponibilização dos medicamentos à população e a continuidade desse fornecimento.

Nesse sentido, contribuição importante poderia ser aportada pela Agência Nacional de Vigilância Sanitária (ANVISA), agência reguladora que, dentre outras funções, realiza o monitoramento dos preços de mercado dos medicamentos. Não apenas acompanha e controla a evolução dos preços desse tipo de produto, como também acompanha, por meio de relatórios de comercialização enviados pela indústria, a real disponibilização dos medicamentos no mercado. Apesar de registrados pela Anvisa, isto é, aprovados pela autoridade sanitária competente para ingressarem no mercado, muitos medicamentos e apresentações de medicamentos simplesmente não são efetivamente disponibilizados à população. Uma das possíveis razões para não mais se disponibilizar no mercado um medicamento causa espécie a quem dela se apercebe: o desinteresse da própria empresa detentora de registro na continuidade de sua comercialização. Com efeito, o Estado ainda não está preparado para adotar medidas regulatórias adequadas a coibir os comportamentos empresariais que sobrepõem estratégias comerciais aos interesses e à saúde da população.

A Lei $n^{\circ}$. 6.360/1976 impõe que devem ser registrados os medicamentos, entre outros produtos sujeitos à vigilância sanitária. Tal análise prévia impunha-se como obrigatória como forma de assegurar à população a qualidade, a segurança e a eficácia dos medicamentos por ela consumidos. Por outro lado, não se pode perder de vista que cabe também ao mesmo Estado promover o desenvolvimento econômico, industrial, científico e tecnológico do país.

Embora o registro ocorra previamente à entrada do produto no mercado, a atuação do Estado, com vistas a garantir a segurança da população, só se pode fundamentar no conhecimento científico divulgado à época da concessão do registro, daí a necessidade de ser regularmente renovado. Ora, ocorre que a lógica de renovação periódica do registro de produtos sujeitos a vigilância sanitária constitui regra que estabelece o papel do Estado regulador apenas no que se refere à 
possibilidade de disponibilização de determinado produto no mercado, desde que atendidos os requisitos de qualidade, segurança e eficácia.

Trata-se, porém, de um marco legal anterior à Constituição Federal de 1988. No novo contexto constitucional, um registro não pode constituir-se apenas num ato de anuência do Estado para a fabricação e a disponibilização de determinado produto no mercado, mas representa também, para o registrante, o dever de que tal produto registrado seja, de fato, disponibilizado à população. Não fariam sentido os esforços do Estado para avaliar técnica e cientificamente um produto, anuindo com sua entrada no mercado brasileiro (isto é, concedendo-lhe um registro) se tal produto não puder ser consumido pela população.

Os medicamentos têm um papel essencial para a efetivação das políticas de saúde. Não se está, contudo, a defender que as políticas de saúde devam resumir-se ao tratamento medicamentoso, mas não se pode negar que do medicamento pode depender o tratamento e mesmo a continuidade da vida de alguém. Por isso, aqui interessa compreender por que alguns desses medicamentos não estão (mais) registrados na Anvisa e disponíveis no mercado brasileiro. Com isso, também se apontam outros aspectos para os quais os Poderes públicos devem estar atentos quando do enfrentamento e da resolução das ações individuais que pleiteiam o fornecimento de medicamentos pelo Estado.

\section{A constitucionalização da saúde e a estruturação de um sistema único}

O tratamento constitucional da saúde e a posterior promulgação da Lei Orgânica da Saúde (LOS), ainda que mediados por cerca de dois anos, constituem marcos do mesmo momento histórico de afirmação das propostas do Movimento de Reforma Sanitária, em que a Lei traduz os princípios conquistados e insculpidos na Constituição (Marques e Ibañez, 2006, p. 11). A Constituição Federal de 1988 representou um marco importante para a construção democrática do Brasil (Carvalho, 2003), em especial para o campo da saúde.

Em decorrência de intensa mobilização política dos profissionais de saúde que, desde o regime militar, clamavam pela formulação de um novo modelo de atenção à saúde, no que se chamou Movimento Sanitário (Escorel, 1998), foi a de 1988 a Carta Constitucional que primeira e especificamente tratou da saúde em seu texto como um direito (Delduque e Oliveira, 2008). "Nenhum texto constitucional se refere 
explicitamente à saúde como integrante do interesse público fundante do pacto social até a promulgação da Carta de 1988." (Dallari, 1995, p. 23.)

Saúde não significa mais a mera ausência de doenças. Vários autores, dentre os quais Dias (2002) e Schwartz (2001), têm observado que o preâmbulo da Constituição da Organização Mundial de Saúde (OMS) já apontava a saúde como o completo bem-estar físico, mental e social e não apenas a ausência de doenças. Esse conceito influenciou fortemente o atual texto constitucional brasileiro sobre a matéria. Assim, podendo-se mesmo afirmar que, até então, a matéria fora praticamente ignorada do ponto de vista constitucional (Rocha, 1999; Raeffray, 2005). A Constituição Federal de 1988, então, inovou ao tratar da saúde nos seguintes termos:

Art. 196. A saúde é direito de todos e um dever do Estado, garantido mediante políticas sociais e econômicas que visem à redução do risco de doença e de outros agravos e ao acesso universal e igualitário às ações e serviços para sua promoção, proteção e recuperação.

No entanto, a saúde não foi alçada ao patamar constitucional de maneira isolada. Reforçando a importância conferida pelo legislador constituinte às políticas públicas de saúde, também se previu um sistema que, por suas características, deveria fazer face aos problemas de saúde da população brasileira. A instituição de um sistema de saúde público, dotado de uma rede de serviços de saúde integrada, regionalizada e hierarquizada, representa a solução encontrada pelo Poder Público para garantir a todos o direito à saúde (Silva, 2008).

Em que pese a disciplina constitucional da saúde bastante detalhada (Carvalho, 2003), ainda ficara em aberto a necessidade de alguma regulamentação infraconstitucional, para disciplinar esse Sistema Único de Saúde (SUS). A Lei Orgânica da Saúde (LOS), constituída por duas Leis (as Leis $n^{\circ} .8 .080$ e n. 8.142/1990) serviu para estruturar legalmente esse Sistema,

(...) tornando claros seus objetivos e suas atribuições, as diretrizes que devem orientar a sua organização, direção e gestão, a forma como estão distribuídas as tarefas entre as três esferas de poder e a forma de participação da comunidade na gestão do sistema em cada uma dessas esferas; disciplina a participação dos serviços privados na prestação de assistência à saúde e a formulação e execução da política de recursos humanos na área da saúde; organiza o financiamento do SUS, tratando expressamente dos recursos, da gestão financeira, do processo de planejamento e do orçamento, inclusive das transferências intergovernamentais de recursos financeiros. (Dallari, 2006a, p. 27.) 
Cumpre registrar que a Lei $\mathrm{n}^{\circ}$. 8080/90 expressamente dispôs estarem incluídas no âmbito do SUS as ações de "assistência terapêutica integral, inclusive farmacêutica" (art. 6, I, “d”). Esta foi a fórmula encontrada pelo legislador para especificar o princípio da integralidade.

Outra ação importante no âmbito do SUS e de relevância para o tema que nos ocupa é a Vigilância Sanitária, cuja definição passou a constar expressamente do texto legal. Necessário, porém, aprofundar a articulação entre esses campos da saúde pública, de modo que um possa compreender os impactos de suas ações sobre o outro e reorganizar-se para atender às finalidades comuns de proteger, promover e recuperar a saúde da população. Esses deveres para com a saúde da população, aliás, são comuns a todos os órgãos do sistema (ainda que se manifestem de maneiras diferentemente preponderantes), haja vista sua unicidade.

\section{Políticas públicas de saúde e a política de assistência farmacêutica}

Para a concretização do direito à saúde, impende que o Estado brasileiro adote uma série de políticas públicas, não apenas na área da saúde, mas compreendidas de forma mais ampla como políticas sociais e econômicas. Nas palavras de Carvalho (2003, p. 25), "a implementação do direito à saúde vincula-se intrinsecamente a elaboração e realização de políticas públicas". Como também observa Schwartz (2004, p. 125), "A Constituição aumenta a possibilidade, por intermédio do Direito, da concretização das políticas públicas ali anunciadas".

O art. 196 [da Constituição Federal de 1988] (...) estabelece a garantia do direito à saúde por meio do dever do Estado de implementar políticas sociais e econômicas que visem à redução do risco de doenças e de outros agravos e ao acesso universal e igualitário às ações e serviços para sua proteção, promoção e recuperação. (Massa-Arzabe, 2006, p. 64 - destaque no original)

No caso das políticas de saúde, a partir dos conceitos analisados, podese concluir que a política pública de saúde no Brasil se configura no Sistema Único de Saúde desde as disposições constitucionais sobre a matéria (Dallari, 2006b). No caso do Sistema Único de Saúde, nele estão reunidas e incluídas as políticas de saúde, em razão de seu caráter único, universal e integral.

As políticas públicas, aqui, explicitamente constituem a garantia do direito social à saúde, definindo a norma constitucional os objetivos de tais políticas, isto é, o objetivo final e amplo de garantia do direito de todos à saúde é de ser atingido pelo objetivo específico de redução de riscos e de observância dos princípios de universalidade e igualdade 
no acesso às ações e serviços de proteção, promoção e recuperação da saúde. (Massa-Arzabe, 2006, pp. 64/65 - destaque no original)

Especificando um pouco as políticas de saúde, Nóbrega (2008) observa que saúde e medicamentos estão estreitamente ligados, sendo difícil pensar a saúde ou a doença sem pensar em medicamentos. A importância do medicamento para a saúde é tanta que alguns autores chegam a defender que sua fabricação deveria ser atribuição exclusiva do Estado, resignando-se, porém, aos argumentos da realidade que demonstram não haver recursos suficientes para isso:

$\mathrm{Na}$ qualidade de bem público e cujo uso, não uso ou mau uso afeta a totalidade da população, o medicamento deveria ser monopólio do Estado o qual deveria desenvolvê-lo, fabricá-lo, trabalhar na adequação das formulações disponíveis e colocá-lo gratuitamente à disposição da população. Entretanto, tal característica de acesso gratuito, universal e de monopólio estatal de todo o ciclo de desenvolvimento-produção-distribuição não ocorre em país nenhum do mundo, mesmo naqueles mais econômica ou socialmente mais avançados. [sic] (Rummel, Chinchilla e Neves, 2006, p. 184)

Com efeito, o Estado não dispõe dos recursos para produzir de forma monopolística e eficiente os medicamentos de que a população necessita. Da mesma forma, também não há recursos o suficiente para atender às demandas da população por todo e qualquer medicamento, sem que o Estado organize prévia e minimamente a sua atuação no fornecimento desses medicamentos.

É certo que o Estado não detém recursos para atender todas as crescentes demandas por medicamentos, e que um ente da Federação não possui estrutura suficiente para suprir as necessidades de sua população. É necessário, portanto, criar condições para que os direitos enunciados possam se traduzir em um real acesso da população aos medicamentos. Para tanto, é de suma importância a elaboração de políticas públicas que definam e organizem as ações estatais. (Nóbrega, 2008, p. 310)

Para garantir o acesso da população aos medicamentos, num dos aspectos da concretização das políticas públicas de saúde, cabe ao Estado, intervir no setor sanitário de medicamentos.

Em relação ao mercado farmacêutico, esta intervenção pode se dar de forma indireta, pela distribuição gratuita de medicamentos, pelo tabelamento de preços, pela política de genéricos, pelo uso do instituto jurídico da licença compulsória como forma de quebra de patentes e também pela produção e comércio de fármacos com preços subsidiados. Neste mesmo âmbito, a intervenção indireta se dá pela regulamentação e fiscalização do setor, com a obrigatoriedade de licenciamento em órgão de Vigilância Sanitária para produção, distribuição e dispensação de drogas, a exigência de responsável técnico farmacêutico, a proibição de exposição à venda de produtos estranhos ao comércio farmacêutico, a vedação da publicidade de medicamentos de uso controlado. (Oliveira, 2007, p. 86) 
Nesse sentido, procurando organizar as ações estatais na área de medicamentos, o Ministério da Saúde publicou a Portaria nº 3.916/1998, estabelecendo a Política Nacional de Medicamentos, de acordo com as diretrizes da Organização Mundial da Saúde (OMS) (Oliveira, Bermudez e Osorio-de-Castro, 2007). Um dos eixos dessa política está na regulação econômica do setor, o que envolve medidas para além do mero controle de preços no mercado, importando ainda na atuação estatal na produção de medicamentos, no estabelecimento de uma política para medicamentos genéricos e na utilização das salvaguardas previstas na legislação de propriedade intelectual, que garantam a produção de um medicamento necessário às políticas de saúde pública (a exemplo do licenciamento compulsório)

Em um regime liberal de livre iniciativa, o alto custo do produto ofertado não constitui um problema em si mesmo. Imagine-se o mercado consumidor como uma pirâmide. Para um produto que possui uma demanda natural no mercado, um preço baixo tende a torná-lo acessível à base [da pirâmide]. Na medida em que o preço se eleva, somente os consumidores mais próximos ao topo podem ter acesso ao produto. Prosseguindo neste movimento, o preço chegará à sua cotação máxima, quando somente os consumidores da cúspide poderão adquiri-lo.

No entanto, para o fornecedor, esse acréscimo nos preços ofertados não implica necessariamente perda de lucros. Ao contrário, ao focar os consumidores cativos e de alta renda, o empresário poderá inclusive aumentar a sua estimativa de lucro.

Por se tratar de um produto de evidente necessidade pública, a lógica de mercado acima explicitada não se aplica em sua inteireza aos medicamentos. Cabe ao Estado promover políticas econômicas que garantam o acesso global. (Oliveira, 2007, p. 77)

Outro dos eixos da Política Nacional de Medicamentos estabelecida em 1998, o da assistência farmacêutica, foi tratado como uma política específica, através da Resolução $n^{\circ}$. 338/2004, do Conselho Nacional de Saúde (CNS), tal a sua importância. Essa Resolução reafirmou, dentre os princípios da política de assistência farmacêutica, sua relação intrínseca com as políticas de saúde do país. De outro lado, ressaltou a sua transversalidade, registrando que mantém pontos de contato com outras políticas setoriais, a exemplo da referida política de medicamentos, mas também de ciência e tecnologia, de desenvolvimento industrial e de formação de recursos humanos, dentre outras políticas setoriais.

Interessante ainda observar que entre os eixos dessa política de assistência farmacêutica apontados há alguns que se relacionam à atuação do órgão federal de Vigilância Sanitária, como a regulação e o monitoramento de mercado de insumos e produtos estratégicos para a saúde e a promoção do uso racional de medicamentos. 
No entanto, no eixo em que mais claramente se evidencia a necessidade de atuação da Vigilância Sanitária, registra-se apenas a necessidade de uma política que garanta o acesso da população a produtos seguros, eficazes e com qualidade. Ou seja, reforça-se o caráter já tradicional das ações de Vigilância Sanitária, perdendo-se a oportunidade de articular mais profundamente a sua atuação às políticas de assistência farmacêutica.

Relacionando os eixos de regulação sanitária e assistência farmacêutica da Política Nacional de Medicamentos, os medicamentos constantes das políticas públicas devem estar previamente registrados junto ao órgão competente de Vigilância Sanitária, uma vez que não seria lícito ao Estado descumprir preceito legal que ele mesmo impôs como instrumento para prevenir riscos à saúde da população decorrentes do consumo de um medicamento não aprovado.

Por outro lado, importa também observar que também se podem vislumbrar outras situações de risco para a saúde do paciente decorrentes do não-consumo de um medicamento registrado, em razão de interrupção na sua produção e/ou distribuição. Assim, a falta de um tratamento também representa riscos para a saúde do mesmo paciente. Inadmissível, porém, é que o risco do não-consumo do medicamento decorra de uma decisão empresarial que resultou na interrupção da fabricação de um medicamento que já havia sido analisado e aprovado pela autoridade sanitária competente. Trata-se de situação que claramente exige a intervenção do Estado para regular a questão, revelando o quanto as ações de Vigilância Sanitária (em particular, o registro de medicamentos) se encontram desarticuladas com outras ações de saúde, a exemplo das de assistência farmacêutica. Vários seriam os exemplos de medicamentos registrados, isto é, analisados e aprovados pela autoridade sanitária competente que simplesmente deixam de ser fabricados ou nunca foram fabricados, exigindo uma intervenção regulatória do Estado para que se venha a garantir a disponibilização de tais medicamentos no mercado brasileiro (Bieber, 2009).

\section{Sistema Nacional de Vigilância Sanitária}

Com a Carta Magna, a Vigilância Sanitária passou a ser um imperativo constitucional, inserida no campo de atuação do SUS. Em 1988, definiram-se as atividades tradicionalmente do campo da Vigilância Sanitária como atribuição do 
SUS, o que resultou na definição legal de Vigilância Sanitária por meio do art. $6^{\circ}, \S 1^{\circ}$, da Lei Orgânica da Saúde (Lei 8.080/90).

Apesar da ainda maior importância que se buscou conferir à Vigilância Sanitária, alçando-a ao texto constitucional como parte integrante de um Sistema Único de Saúde, a verdade é que a Vigilância Sanitária continuou sendo vista como um órgão burocrático e, em razão disso, cada vez mais esvaziada e fragilizada (Souto, 2004; Lucchese, 2008).

Num contexto de muitas denúncias das fragilidades do Sistema de Saúde e, no particular, da Vigilância Sanitária, o Poder Executivo realizou estudos para reestruturação de toda a Vigilância Sanitária, importando na organização de um sistema próprio, como um subsistema do Sistema Único de Saúde, cuja coordenação seria exercida, na esfera federal, por uma agência reguladora.

Além das atribuições específicas decorrentes da função de coordenação nacional do novo Sistema, coube à autoridade sanitária federal o controle prévio (realizado através do registro) dos produtos sujeitos à Vigilância Sanitária. Nele, o instrumento de prevenção de riscos e de promoção da saúde se confunde com um instrumento de regulação, uma vez que se revela um ato administrativo essencial à entrada do medicamento no mercado.

É uma garantia à saúde pública que a produção e fabricação de certos produtos sejam submetidas ao regime da legislação sanitária e ao poder de polícia sanitária. O Estado-administrador vale-se de licenças, autorizações, registros, para controlar os bens que possam interferir com a saúde, a exemplo de alimentos, equipamentos médicos e produtos sanitários. (Horta, 2002, p. 53)

A atribuição dessa função à autoridade sanitária federal decorre da necessidade de se estabelecerem critérios únicos à circulação de produtos em todo o território nacional. Com isso, busca-se garantir uma uniformidade de entendimento e de tratamento, bem como uma economia de recursos, ao emitir-se um juízo único, que garantirá a livre circulação do produto em todo o território nacional.

\section{Marco legal do registro de medicamentos e suas relações com a política de assistência farmacêutica.}

No período entre 1969 e 1977, foram estabelecidas as principais leis da Vigilância Sanitária que, em sua maioria, continuam vigentes até os dias atuais. Elas revelavam uma preocupação com a modernização das normas relativas à produção industrial e ao comércio de produtos que, historicamente, submeteram-se a um 
regime de vigilância sanitária, visando à preservação da saúde da população (Lucchese, 2008). Com isso, estabeleceram-se as normas aplicáveis às indústrias nacionais instaladas e às indústrias estrangeiras que se propunham instalar no Brasil.

As normas relativas ao registro dos medicamentos, dentre outros produtos sujeitos ao regime de vigilância sanitária, foram estabelecidas pela Lei $n^{\circ}$. 6.360, de 1976.

O registro, cujo conceito legal está no art. $3^{\circ}, \mathrm{X}$, dessa lei, tem natureza autorizativa, constituindo-se em ato vinculado sem o qual não se poderão fabricar e comercializar os medicamentos, conforme, aliás, é a disposição expressa do art. 12, caput. A principal regra estabelecida por essa lei está na proibição de fabricação, comercialização ou entrega para consumo de qualquer dos produtos nela disciplinados antes de serem previamente registrados junto à autoridade sanitária federal.

A finalidade principal do registro é garantir que sejam entregues à população medicamentos que contenham componentes eficazes e que atendam à destinação terapêutica indicada. Outro objetivo importante é o poder que o Ministério da Saúde, através do órgão competente, tem para, conhecendo os diversos tipos de substâncias usadas no País, a qualquer momento, por motivos de risco potencial à saúde ou por não serem mais benéficas do ponto de vista clínicoterapêutico, identificar quem as utiliza, proibir o seu uso ou exigir que as fórmulas sejam modificadas. (Horta, 2002, pp. 54/55)

Os dispositivos abaixo transcritos, uma vez que se referem a todos os produtos disciplinados pela Lei $n^{\circ}$. 6.360/1976, referem-se aos medicamentos, objeto desta análise particular:

Art. 12 - Nenhum dos produtos de que trata esta Lei, inclusive os importados, poderá ser industrializado, exposto à venda ou entregue ao consumo antes de registrado no Ministério da Saúde.

$\S 1^{\circ}$ - O registro a que se refere este artigo terá validade por 5 (cinco) anos e poderá ser revalidado por períodos iguais e sucessivos, mantido o número do registro inicial.

Como se pode observar, a obrigatoriedade de registro, estabelecida no caput do artigo como regra geral para a fabricação e a comercialização lícita do produto, não resulta num ato administrativo de validade temporal indeterminada. O legislador houve por bem limitar temporalmente a validade dos registros concedidos numa estratégia de tornar frequente as avaliações relativas à segurança, à qualidade e à eficácia (no caso dos medicamentos). Com isso, possibilita-se não apenas uma nova análise do dossiê de registro, mas também a formulação de exigências (fundamentadas em normas regulamentares supervenientes à concessão do registro 
inicial), de maneira que a situação do registro possa sempre corresponder aos conhecimentos científicos disponíveis sobre o produto (no caso, o medicamento). O registro, então, é concedido e válido por um período de cinco anos a contar de sua publicação na imprensa oficial (art. 12, $\S 4^{\circ}$ ), e será válido por novos períodos de iguais cinco anos, contando-se a partir do dia seguinte ao fim do período anterior, enquanto sua renovação continuar sendo concedida pelo órgão federal de Vigilância Sanitária.

Entretanto, o que fazer se ou quando o medicamento, cuja renovação de registro não foi pedida ou o foi intempestivamente, é importante para a política pública de assistência farmacêutica do Ministério da Saúde ou mesmo de um estado, do Distrito Federal ou de um município?

Para responder a tal questão, é preciso compreender o caráter público envolvido na concessão de um registro de produto sujeito a vigilância sanitária. Esse caráter público decorre não apenas de a concessão de registro, ou sua negativa, constituir-se num ato de polícia sanitária, mas, sobretudo, no fato de que o Poder Público, ao envidar esforços para empreender uma análise de que poderá resultar na concessão de um registro, manifestando-se favoravelmente ao pleito, não apenas está a afirmar que o requerente do registro pode comercializar o produto fabricado, mas que também é do interesse público que tal produto seja realmente disponibilizado ao consumo. Da mesma forma, mas bem mais evidentemente, ao pronunciar-se contrariamente à concessão do registro, está a autoridade sanitária a afirmar não ser do interesse público que um determinado produto seja fabricado e comercializado no país, nas condições descritas em seu dossiê de registro. Desse caráter público decorre também a proibição legal de se conceder a renovação de um registro ao fabricante ou importador que não o disponibilizar dentro do prazo estabelecido por Lei. Embora indicativo do entendimento acerca do caráter público revelado na concessão de um registro de medicamentos, a questão é tratada apenas parcialmente, uma vez que deixa sem resposta as situações em que um produto deixa de ser, intencionalmente, fabricado e disponibilizado à população no mercado, segundo as condições do registro concedido.

Há, portanto, na Lei $n^{\circ}$. 6.360/1976, sérias lacunas legislativas que não protegem os interesses do Estado na implementação de uma política farmacêutica, face aos interesses privados das empresas detentoras dos registros de medicamentos. 
As normas de apuração de infrações à legislação sanitária federal foram estabelecidas por outra lei da mesma época: a Lei $n^{\circ} .6 .437$, de 1977, que, além de estabelecer o rito administrativo de apuração, tipificou as infrações sanitárias (Hirsch, 2003). Na sua redação original, não havia qualquer previsão legal relativa à interrupção da produção e da comercialização de medicamento pela omissão da empresa detentora do registro quanto à sua renovação, que permitisse enquadrar tais comportamentos prejudiciais ao sistema público de saúde e, em especial, às políticas de assistência farmacêutica como infração sanitária. Atualmente, porém, a Lei $n^{\circ}$. 6.437/1977 encontra-se alterada pela Medida Provisória nº 2.190-34/2001:

Art. 10. São infrações sanitárias:

$(\ldots)$

XXXIX - interromper, suspender ou reduzir, sem justa causa, a produção ou distribuição de medicamentos de tarja vermelha, de uso continuado ou essencial à saúde do indivíduo, ou de tarja preta, provocando o desabastecimento do mercado:

pena - advertência, interdição total ou parcial do estabelecimento, cancelamento do registro do produto, cancelamento de autorização para funcionamento da empresa, cancelamento do alvará de licenciamento do estabelecimento e/ou multa;

$\mathrm{XL}$ - deixar de comunicar ao órgão de vigilância sanitária do Ministério da Saúde a interrupção, suspensão ou redução da fabricação ou da distribuição dos medicamentos referidos no inciso XXXIX:

pena - advertência, interdição total ou parcial do estabelecimento, cancelamento do registro do produto, cancelamento de autorização para funcionamento da empresa, cancelamento do alvará de licenciamento do estabelecimento e/ou multa;

Por esses dispositivos, poder-se-ia caracterizar como infração sanitária os problemas de interrupção da produção e da comercialização que se vem tentando enfrentar. Ocorre que a dicção legal é, em verdade, extremamente limitada, de maneira que os interesses públicos na produção do medicamento não permanecem resguardados (Bieber, 2009). Uma leitura inicial do art. 10, XXXIX e XL, da Lei $n^{\circ}$. $6.437 / 1977$ pode levar a um entendimento inicial de que interromper, suspender ou reduzir a fabricação e/ou distribuição de medicamentos, em prejuízo das políticas de assistência farmacêutica constituiria uma infração administrativo-sanitária. Entretanto, não é isso que a prática revela, uma vez que basta uma comunicação à Anvisa para afastar a ilicitude da conduta. Não se pode afirmar, portanto, que a interrupção da fabricação e da distribuição de um medicamento, decorrente da caducidade do seu registro, por mais omissa que tenha sido a empresa dele detentora e por mais que prejudique as políticas de assistência farmacêutica, constitua uma infração à legislação sanitária federal. Assim, também na Lei que configura as infrações à 
legislação sanitária federal se pode observar a existência de importantes lacunas que deixam o Estado desguarnecido e refém das empresas detentoras dos registros (indústrias instaladas no Brasil e importadoras), para a concretização das suas políticas de assistência farmacêutica.

A partir da análise acima, fica evidente que a legislação sanitária atualmente vigente, embora se preste a cumprir os propósitos de garantir a qualidade, a eficácia e a segurança, no sentido de realizar a missão da Vigilância Sanitária de prevenir, eliminar e reduzir os riscos envolvidos no consumo de medicamentos (Rosenberg, 2001, pp. 103/104), não basta para defender o interesse público consistente na implementação de uma política de assistência farmacêutica e na sua continuidade. Não há norma que expressamente garanta a continuidade da produção e da distribuição do medicamento de interesse das políticas públicas de saúde após o fim da validade do seu registro (ainda que temporariamente) à semelhança da obrigação que o Código de Proteção e Defesa do Consumidor impõe aos fabricantes de ainda garantirem, durante período razoável de tempo, a assistência técnica e peças para consertos e reposição após a retirada do produto no mercado (art. 32, parágrafo único, da Lei $n^{\circ}$. 8.078/1990).

\section{Estado regulador}

Organismos internacionais impuseram ao restante do mundo o receituário neoliberal e a consequente diminuição do Estado de Bem-Estar Social, apontando para uma readequação das atividades estatais, agora como reguladora da atuação dos agentes da iniciativa privada (Mello, 2001, p. 89).

O modelo aqui desenvolvido, notadamente a partir da Reforma Administrativa da década de 90 , propõe uma verdadeira diminuição da atividade estatal, levando-se em conta as atividades desenvolvidas pelo Estado.

(...)

Em verdade, o Estado Brasileiro, que ainda buscava, ao início da década de 90, achar-se enquanto Estado Democrático de Direito, viveu um período de busca pela desestatização, com uma série de privatizações e quebras de monopólios, nos mais diversos setores da vida sócio-econômica. (Peixoto, 2006, pp. 99/100)

A abertura econômica do país no fim da Década de 1980 e no início da seguinte tornou o país mais suscetível aos influxos e às crises da economia mundial. O aparelho burocrático das empresas estatais, por sua vez, seria pesado demais para mover-se na velocidade requerida por uma economia cada vez mais globalizada. Urgia privatizá-las, para cumprir as obrigações impostas pela agenda neoliberal 
assumida junto aos organismos internacionais de crédito. Para implantar as mudanças estruturais que reduzissem o tamanho do Estado, formulou-se um discurso que procurou demonstrar a crise por que passaria o modelo de Estado de fins da Década de 1970, agigantado e interferente na economia como um agente econômico, atuando em mercados monopolísticos e mesmo enfrentando a concorrência das empresas privadas em outros mercados mais livres. As modificações burocráticoadministrativas daí decorrentes assumiram um caráter muitas vezes irreversível (Coutinho, 2002). Trata-se de fenômeno recente, em que a idéia de regulação está associada às formas de organização de um mercado de que o Estado se pode valer, seja pela concessão de serviços públicos, seja pelo exercício do poder de polícia administrativa.

O Estado, que havia abandonado o modelo do Estado mínimo do liberalismo clássico, abandona também sua atuação como agente econômico e passa a atuar nessa área apenas como um interventor (Bruna, 2003). Essa intervenção de que fala este autor trata, portanto, não da intervenção na economia como agente econômico, mas de uma atuação que estabelecesse as regras e garantisse a ordem em mercados específicos.

A Função estatal de regular, portanto, está associada ao dever fundamental do Estado de ordenar o corpo social para que este se organize harmonicamente.

(...)

[Ela] aumenta na medida em que o Estado moderno fica cada vez mais complexo, tanto no que se refere às diversidades sociais existentes, como principalmente no que diz respeito a uma necessidade de dinamização do Direito como instrumento estatal de controle e organização social. (Aith, 2004, p. 65)

No entanto, para dar conta de tamanhas complexidades e exercer adequadamente as funções regulatórias, foi necessário repensar as estruturas administrativas do aparelho burocrático de Estado. Numa transposição do modelo americano (Moreira Neto, 2003) de regulação das atividades econômicas, criaram-se no Brasil as Agências Reguladoras Federais, entes da Administração Indireta a que a Lei atribui competência para regular setores determinados da economia.

A lógica da atuação da Administração Pública deixa de ser o controle de procedimentos (ou de meios) para ser pautada pelo controle de resultados, buscando a máxima eficiência possível. Para tanto, um dos pontos-chave da Reforma é atribuir ao administrador público parte da autonomia de que goza o administrador privado, com a criação de órgãos independentes (as "agências") da estrutura administrativa tradicional, formados por critérios técnicos, não políticos. (Bercovici, 2006, p. 150) 
Sobre a necessidade de o Estado regular as atividades da iniciativa privada em função do interesse coletivo, contrariando, de certa maneira, a teoria liberal, a observação de Oliveira (2007, pp. 72/73) é precisa:

Todavia, nem sempre a mão invisível terá capacidade para atender a todos os interesses sociais. De fato, o desenvolvimento natural das forças de mercado implica uma gradativa concentração empresarial, com tendência à assimetria de informações. O fornecedor passa a centralizar poder em detrimento do consumidor. Este processo contraria a lógica de um mercado que se autorregula, pelo inerente surgimento de deformações.

$\mathrm{Na}$ busca (em si, legítima) pelo lucro, por vezes o fornecedor de bens e serviços ultrapassa o interesse social, provocando conseqüências negativas ao meio-ambiente, aos trabalhadores e ao consumidor.

O Estado interventor surge com este fundamento, de alinhavar a atividade econômica ao interesse público. A supremacia do interesse público sobre o privado, bem como a função social da propriedade, legitimam a sua atuação no equilíbrio das relações econômicas, porquanto Poder Público organizado pela sociedade, atuando em cima de agentes produtivos e até como um deles, com o intuito de corrigir as deformações próprias do sistema. (Destaque no original)

Segundo Aith, entre as competências da função estatal de regulação está a normativa:

A regulação abrange, assim, toda a ação voltada à produção de normas jurídicas que determinem direitos, imponham deveres e definam obrigações, prevendo inclusive, quando necessário, mecanismos de sanção aos que não observarem seus ditames. (2004, p. 65)

No mesmo sentido, Galvão (2006) observa que os limites da ação regulatória de uma agência reguladora decorrem da lei que a instituiu. As normas por ela editadas dentro desses limites estariam autorizadas tacitamente pelo Poder Legislativo. Na mesma obra, esse autor alerta ainda para a necessidade de analisar a fundamentação jurídica e constitucional para a atuação normativa das agências reguladoras, uma vez que essa construção se revelaria precária se alicerçada apenas sobre a autorização legislativa.

As normas editadas pelas agências têm, notadamente, um tortuoso vínculo de legitimação normativo-hierárquico com a Constituição. Essa circunstância decorre do fato de a atuação das agências resultar de uma autorização legal e de autorização regulamentar (em esfera iminentemente instrumental, tendo em vista que a lei e o regulamento tratam de seu funcionamento e diretrizes a serem seguidas) e as normas por ela produzidas espelham disposições legais materiais sem que haja necessariamente interposição do regulamento. (Galvão, 2006, p. 37)

No caso da Agência Nacional de Vigilância Sanitária, a Lei nº 9.782/99, que a criou, atribuiu-Ihe competências normativas em seu art. $7^{\circ}$, III, no que se refere aos 
produtos e serviços sujeitos ao regime de vigilância sanitária. Estes são definidos nos dois primeiros parágrafos do artigo seguinte.

Também essa nova regulamentação não significa que as normas editadas pelo órgão regulador terão o mesmo status hierárquico-normativo que as Leis, que não significa que não devam ser cumpridas e obedecidas como se de leis se tratasse. Isso apenas significa que, havendo lei sobre o assunto (anterior ou posterior à regulamentação), a norma administrativa deverá adequar seu conteúdo aos ditames legais. Nesse sentido, o caput do art. $8^{\circ}$ da Lei ${ }^{\circ}$. 9.782/1999 é expresso em determinar que a Anvisa deve regulamentar os produtos e serviços que envolvam risco à saúde, "respeitada a legislação em vigor".

\section{Conclusões}

A Anvisa, a partir do registro de medicamentos, teria uma contribuição especial às políticas de saúde e, em especial à política de medicamentos, se procedesse a um verdadeiro enfrentamento dos interesses econômicos empresariais que, com não rara freqüência, sobrepõem-se aos interesses da população. Porém, uma legislação relativamente antiga e o insulamento burocrático da Agência não têm permitido que sua atuação seja repensada, para além da garantia de segurança, eficácia e qualidade dos medicamentos.

Evidentemente, entre o estabelecimento do marco legal do registro de medicamentos e o momento atual, muitas transformações ocorreram. Algumas, como a constitucionalização da saúde como um direito de todos e um dever do Estado, representaram uma verdadeira revolução, pela grandiosidade da mudança de paradigmas que operou, tornado a saúde universal e seu atendimento integral. Outras, como os avanços científicos na área da medicina e da produção de medicamentos, aconteceram sem rupturas, mas muito mais sutilmente; da mesma forma, as estratégias comerciais das empresas que investem em pesquisa e desenvolvimento de novas drogas.

O resultado, porém, foi que, na nova conformação constitucional da saúde e do Estado brasileiro, as ações a que esse Estado estava constitucional ou legalmente obrigado estavam de tal maneira ensimesmadas que deixaram de atuar sinergicamente, aumentando os efeitos de suas atuações em benefício da saúde da população. Significa que o Estado regulador que começou a se configurar no Brasil a partir da implantação da agenda neoliberal, aprofundando-se ao longo da Década de 
1990, sequer atuava convenientemente nas suas funções de regulação. Evidentemente, essa situação não era sem razões, como observa Bercovici:

A regulação significou o desmonte da estrutura do Estado, o sucateamento do Poder Público e o abandono de qualquer possibilidade de implementação de uma política deliberada de desenvolvimento nacional. (Bercovici, 2006, p. 153)

No entanto, como bem registraram Rummel, Chinchilla e Neves (2006, p. 194),

É função do Estado de mediar os distintos interesses envolvidos no mercado de medicamentos, de forma que os diferentes atores envolvidos (fabricantes, distribuidores e usuários) não imponham seus desejos de forma unilateral sobre o interesse coletivo.

Ao apontar para os aspectos da regulação sanitária uma vez que a essas políticas interessa garantir que os medicamentos consumidos pela população tenham segurança, qualidade e eficácia, estabeleceram-se as bases iniciais para a compreensão da importância da Vigilância Sanitária para as políticas de medicamentos e assistência farmacêutica. Evidentemente, a desarticulação entre esses campos não é casual ou inocente.

A Vigilância Sanitária, desde a sua conformação como espaço institucional, na década de 1970, embora legalmente tivesse como propósito contribuir para a saúde da população, salientou-se muito mais como um espaço burocrático que responde aos interesses do setor produtivo do que em relação à finalidade para a qual foi instituída. (Souto, 2004, pp. 134/135)

Assentando a necessidade de articulação das ações de assistência farmacêutica com as de vigilância sanitária, como mais um instrumento na luta pela garantia do acesso ao medicamento, observou-se, infelizmente uma séria desarticulação entre as ações de vigilância sanitária e tais políticas. As ações de vigilância sanitária só se mostraram capazes de contribuir para tais políticas a partir do estabelecimento de mecanismos que garantam a segurança, a eficácia e a qualidade do medicamento. No entanto, esses aspectos ficam muito aquém do que a ação de registro sanitário pode representar para a assistência farmacêutica, sobretudo porque realizada por uma agência dotada de muitos poderes para desempenhar as suas funções. A legislação referente ao registro de medicamentos continua a conferir às empresas reguladas um protagonismo incoerente com a nova ordem sanitária constitucional quanto às decisões dos medicamentos que serão disponibilizados no mercado aos cidadãos ou dele retirados. $E$ há dispositivos constitucionais e legais, promulgados posteriormente, que fundamentam suficiente para uma atuação mais incisiva do Estado na defesa do interesse público e da continuidade de suas políticas de saúde. 


\section{Referências}

AITH, Fernando Mussa Abujamra. Reflexões Sobre o Princípio da Legalidade na Ciência do Direito Contemporânea. Revista de Direito Sanitário, 5(3): 41-81, nov. 2004. ISSN: 1516417-9.

BERCOVICl, Gilberto. Planejamento e Políticas Públicas: por uma nova compreensão do papel do Estado. In: BUCCl, Maria Paula Dallari (Org.). Políticas Públicas: Reflexões Sobre o Conceito Jurídico. São Paulo: Saraiva, 2006, pp. 143-161. ISBN: 9788502060548.

BIEBER, Luís Bernardo Delgado. Contribuições às Políticas de Saúde a partir da Atuação da Agência Nacional de Vigilância Sanitária e da Análise do Marco Regulatório do Registro de Medicamentos. Monografia (Especialização em Direito Sanitário) Fundação Oswaldo Cruz. Brasília, 2009.

BRUNA, Sérgio Varella. Agências Reguladoras: Poder Normativo, Consulta Pública, Revisão Judicial. São Paulo: Editora Revista dos Tribunais, 2003. ISBN: 8520323812.

BUCCl, Maria Paula Dallari. O Conceito de Política Pública Em Direito. In: BUCCI, Maria Paula Dallari (Org.). Políticas Públicas: Reflexões Sobre o Conceito Jurídico. São Paulo: Saraiva, 2006, pp. 1-49. ISBN: 9788502060548.

CARVALHO, Guido Ivan e SANTOS, Lenir. Sistema Único de Saúde: Comentários à Lei Orgânica da Saúde (Leis 8.080/90 e 8.142/91). São Paulo: HUCITEC, 1995. ISBN: 9788526807235.

CARVALHO, Mariana Siqueira de. A Saúde Como Direito Social Fundamental na Constituição Federal de 1988. Revista de Direito Sanitário, 4(2):15-31, jul. 2003. ISSN: 1516417-9.

CARVALHO, Vinícius Marques de. Regulação de Serviços Públicos e Intervenção Estatal na Economia. In: FARIA, José Eduardo (Org.). Regulação, Direito e Democracia. São Paulo: Fundação Perseu Abramo, 2002, pp.13-25. ISBN: 858646958.

COUTINHO, Diogo R. Privatização, Regulação e o Desafio da Universalização do Serviço Público no Brasil. In: FARIA, José Eduardo (Org.). Regulação, Direito e Democracia. São Paulo: Fundação Perseu Abramo, 2002, pp.67-94. ISBN: 858646958.

DALLARI, Sueli Gandolfi. O Direito Sanitário Como Campo Fundamental para a Vigilância Sanitária. In: MARQUES, Maria Cristina da Costa [et alii]. Vigilância Sanitária: Teoria e Prática. São Carlos: RiMa, 2006a, pp. 15-32. [ISBN n. fornecido].

Os Estados Brasileiros e Direito à Saúde. São Paulo: HUCITEC, 1995. ISBN: 8527102587.

Políticas de Estado e Políticas de Governo: O Caso da Saúde Pública. In: BUCCl, Maria Paula Dallari (Org.). Políticas Públicas: Reflexões Sobre o Conceito Jurídico. São Paulo: Saraiva, 2006b, pp. 247-266. ISBN: 9788502060548.

DELDUQUE, Maria Célia; OLIVEIRA, Mariana Siqueira de Carvalho. Tijolo Por Tijolo: A Construção Permanente do Direito à Saúde. In: COSTA, Alexandre Bernardino [et alii] (Org.). O Direito Achado na Rua: Introdução Crítica Ao Direito à Saúde. Brasília: CEAD/UnB, 2008, pp. 103-111. ISBN: 978-85-7804-025-3. 
DIAS, Hélio Pereira. Direitos e Obrigações Em Saúde. Brasília: ANVISA, 2002. ISBN: 85-88233-08-8.

ESCOREL, Sarah. Reviravolta na Saúde: Origem e Articulação do Movimento Sanitário. Rio de Janeiro: FIOCRUZ, 1998. ISBN: 8585676574.

GALVÃO, Gabriel de Mello. Fundamentos e Limites da Atribuição de poder Normativo às Autarquias Autônomas Federais (Agências Reguladoras). Rio de Janeiro: Renovar: 2006. ISBN: 8571475377.

HIRSCH, Glaicon Joel. Fiscalização e Processo Administrativo-Sanitário: à Luz da Constituição da República. Rio de Janeiro: AIDE, 2003. ISBN: 9788532101815.

HORTA, Marcelo Palis. Aspectos Formais Sobre o Registro de Medicamentos e os Limites da Atuação Judicial. Revista de Direito Sanitário, 3(3):52-68, nov. 2002. ISSN: 1516417-9.

LUCCHESE, Geraldo. Globalização e Regulação Sanitária: Os Rumos da Vigilância Sanitária no Brasil. Brasília: ANVISA, 2008. ISBN: 978-85-88233-39-3.

MARQUES, Maria Cristina da Costa; IBAÑEZ, Nelson. Questões Sobre Política de Vigilância Sanitária no Brasil. In: MARQUES, Maria Cristina da Costa [et alii]. Vigilância Sanitária: Teoria e Prática. São Carlos: RiMa, 2006, pp. 1-14. ISBN: 8576561085.

MASSA-ARZABE, Patrícia Helena. Dimensão Jurídica das Políticas Públicas. In: BUCCI, Maria Paula Dallari (Org.). Políticas Públicas: Reflexões Sobre o Conceito Jurídico. São Paulo: Saraiva, 2006, pp. 51-74. ISBN: 9788502060548.

MELLO, Vanessa Vieira de. Regime Jurídico da Competência Regulamentar. São Paulo: Dialética, 2001. ISBN: 978857500274.

MOREIRA Neto, Diogo de Figueiredo. Direito Regulatório. Rio de Janeiro: Renovar, 2003. ISBN: 9788571473164.

NÓBREGA, Ramiro. Acesso a Medicamentos: Direito Garantido no Brasil? In: COSTA, Alexandre Bernardino [et alii] (Org.). O Direito Achado na Rua: Introdução Crítica Ao Direito à Saúde. Brasília: CEAD/UnB, 2008, pp. 307-318. ISBN: 978-857804-025-3.

OLIVEIRA, Luís Fernando Lima de. Intervenção do Estado no Mercado Farmacêutico - Regulação Econômica Em Prol da Saúde Pública. In: CONTINENTINO, Marcelo Casseb; SANTOS, Marcos André Couto; PEREIRA, André Melo Gomes. Estudantes - Caderno Acadêmico - Edição Comemorativa. Recife: Editora Nossa Livraria, 2007, pp. 71-88. [ISBN n. fornecido].

OLIVEIRA, Maria Auxiliadora; BERMUDEZ, Jorge Antonio Zepeda; OSORIO-DECASTRO, Cláudia Garcia Serpa. Assistência Farmacêutica e Acesso a Medicamentos. Rio de Janeiro: FIOCRUZ, 2007. ISBN: 9788575411315.

PEIXOTO, Marco Aurélio Ventura. Poder Regulamentar da Administração Pública: Os Regulamentos Autônomos Como Ferramentas de Atenção à Dinâmica Social. Recife: Editora Nossa Livraria, 2006. ISBN: 9788588144804.

RAEFFRAY, Ana Paula Oriola de. Direito da Saúde: De Acordo Com a Constituição Federal. São Paulo: Quartier Latin, 2005. ISBN: 8576740265.

ROCHA, Júlio César Sá da. Direito da Saúde: Direito Sanitário na Perspectiva dos Interesses Difusos e Coletivos. São Paulo: LTr, 1999. ISBN: 9788573225563. 
ROSENBERG, Felix J. Mecanismos Legais de Controle da Segurança do Medicamento. Revista de Direito Sanitário, 2(1):102-112, mar. 2001. ISSN: 15164179.

RUMMEL, Davi; CHINCHILLA, Izabela Nunes; NEVES, Eugênio Rodrigo Zimmer. Aspectos Legislativos da Regulação de Medicamentos. Revista de Direito Sanitário, 7(1/2/3):183-194, 2006. ISSN: 1516417-9.

SCHWARTZ, Germano André Döderlein. Direito à Saúde: Efetivação Em Uma Perspectiva Sistêmica. Porto Alegre: Livraria do Advogado, 2001. ISBN: 9788573481860 .

O Tratamento Jurídico do Risco no Direito à Saúde. Porto Alegre: Livraria do Advogado, 2004. ISBN: 857348304.

SILVA, José Afonso da. Curso de Direito Constitucional Positivo. São Paulo: Malheiros, 2008. ISBN: 9788574208404.

SOUTO, Ana Cristina. Saúde e Política: A Vigilância Sanitária no Brasil 1974-1996. São Paulo: Sociedade Brasileira de Vigilância de Medicamentos - SOBRAVIME, 2004. ISBN: 8588284030. 